\title{
Ethnic variation in osteoporosis risk factors: dietary calcium, vitamin D intake and body mass index (BMI)
}

\author{
Yap, S.Y., Aziz, Y., Asma', A. and *Yusof, H.M. \\ School of Food Science and Technology, Universiti Malaysia Terengganu, 21030 Kuala Nerus, \\ Terengganu, Malaysia
}

\section{Article history: \\ Received: 19 April 2019 \\ Received in revised form: 30 \\ May 2019 \\ Accepted: 31 May 2019 \\ Available Online: 11 June 2019 \\ Keywords: \\ Osteoporosis risk factor, \\ Dietary calcium, \\ Vitamin D, \\ Body mass index}

\section{DOI:}

https://doi.org/10.26656/fr.2017.3(6).168

\begin{abstract}
Osteoporosis is the most common bone disease in humans, representing a major public health problem. Few studies have investigated osteoporosis risk factors such as calcium and vitamin D intake, quality of life and body mass index (BMI) among multi-ethnic adults in the Malaysian context. This study aimed to determine the ethnic variation in osteoporosis risk factors among students in Universiti Malaysia Terengganu (UMT). A cross-sectional study via a self-administrated questionnaire was carried out among 198 respondents aged 19 to 25 years from UMT. The data in the present study included a three -day food record and anthropometric measurements. Nutritionist Pro $^{\mathrm{TM}}$ analysis software version 5.3 was used to calculate dietary calcium and vitamin D intake from the diet histories, based on the Nutrient Composition of Malaysian Food Database guidance for the dietary calcium intake and the United States Department of Agriculture (USDA) for vitamin D intake. The data were analyzed using Kruskal-Wallis, Mann-Whitney and ChiSquare tests. The findings indicate the median calcium intake was $348.3 \mathrm{mg} /$ day while for vitamin $\mathrm{D}$ intake was only $1.37 \mu \mathrm{g} /$ day. Indian participants had a significantly lower intake level of calcium ( $243.5 \mathrm{mg}$ /day), followed by Chinese (362.3 mg/day) and Malays ( $440.4 \mathrm{mg} /$ day). The median vitamin D intakes of Malay, Chinese, and Indian adults were $2.15 \mu \mathrm{g} /$ day, $1.37 \mu \mathrm{g} /$ day and $1.14 \mu \mathrm{g} /$ day, respectively. Furthermore, the BMI among respondents at $20.88(6.4) \mathrm{kg} / \mathrm{m}^{2}$ categorized as normal weight. It was found that there was no significant difference ( $p>0.05$ ) in BMI across ethnicity. Lastly, there was a significant association $(p<0.05)$ between ethnicity and calcium intake $(p=0.001)$.
\end{abstract}

\section{Introduction}

Osteoporosis is a major health problem worldwide, particularly in Asia. It is characterized by low bone mass, deterioration of bone tissue, disruption of bone microarchitecture or porous bone, which are associated with higher fracture risk (Kling et al., 2014; Sozen et al., 2017). This chronic progressive disease occurs in both men and women of all races and age groups. This disease generally does not become clinically apparent until a fracture occurs and thus it is described as a "silent thief" (Kamau, 2011).

It is important to recognize osteoporosis risk factors early in life and take appropriate action, as prevention may have an enormous positive impact on bone health in later years. Young people should focus on building the peak bone mass that will keep them in good stead for the rest of their lives (International Osteoporosis Foundation, 2017). Currently, more than one million Malaysians are at risk of developing osteoporosis. About $20 \%$ of men and $51.8 \%$ of women suffer from osteoporosis near the age of menopause (Khan et al., 2014). In contrast to childhood and postmenopausal or elderly subjects, diagnosis and treatment of osteoporosis in young adults remain poorly defined (Ferrari et al., 2012). Hence, the risk factors of osteoporosis should be clearly determined in young adulthood. Family history of osteoporosis and fracture, tobacco consumption, dietary habits, sedentary lifestyle, cigarette smoking, alcohol abuse and caffeine consumption are common factors closely related to the occurrence of osteoporosis. Body mass index (BMI) also affects osteoporosis (Assomaning et al., 2006).

Calcium and vitamin D are two essential nutrients long been recognized as important and required nutrients for their role in bone health and maintenance. Poor calcium and vitamin D status are detrimental to skeletal health (Hawa et al., 2013). In Malaysia, several studies have reported that many individuals are not meeting the daily recommendation of calcium and vitamin $D$ intake. Recommendations for calcium and vitamin D intake for 
adults have increased from $800 \mathrm{mg} /$ day to $1000 \mathrm{mg} /$ day and $5 \mu \mathrm{g} /$ day to $15 \mu \mathrm{g} /$ day, respectively, in the Recommended Nutrient Intake (RNI) 2017 guidelines [National Coordinating Committee on Food and Nutrition (NCFFN), 2017].

In recent years, knowledge about osteoporosis has increased exponentially. However, osteoporosis not only remains under-diagnosed and under-treated in Malaysia. Its prevalence is not well known or documented, other than from a 1997 study on hip fractures (International Osteoporosis Foundation, 2013). There is a lack of data on calcium and vitamin D status among the general population in Malaysia, as most studies have been limited to pockets of populations such as children and women (Rahman et al., 2004; Chee et al., 2010; Mahdy et al., 2014; Zaleha et al., 2015; Fong et al., 2016). There is also a lack of studies on the multi-ethnic adult population on risk factors of osteoporosis in Malaysia. A previous study by Lau et al. (2001) reported the incidence of hip fracture was higher among Chinese women than Malays and Indian. Moreover, the Chinese also has the highest incidence of osteoporosis (Muslim et al., 2011). However, a higher proportion of Indian and Malay respondents had lower vitamin D status as compared to their Chinese counterpart (Green et al., 2008; Nurbazlin et al., 2013; Shafinaz and Moy, 2016). Lack of study based on ethnicity on osteoporosis risk factors in Malaysia. For examples, Chee et al. (2010) focused on calcium intake, vitamin $\mathrm{D}$ and bone health among postmenopausal women in Kuala Lumpur. On the other hand, Hawa et al. (2013) performed a study among Malays women with low-income family in Kelantan. To date, limited study determined both calcium and vitamin D intake status among multi-ethnic. Madhy et al. (2014) investigated calcium intake among antenatal women; whereas Chee et al. (2002) on postmenopausal. For vitamin $\mathrm{D}$, previous studies limited to among children (with epilepsy, aged between 3 and 18 years old), adolescents and women (postmenopausal aged $50-65$ years old and pregnant women) (Rahman et al., 2004; Zaleha et al., 2015; Fong et al., 2016). Therefore, the present study evaluates osteoporosis risk factors among multi-ethnic young adults overall. Ethnic variation in osteoporosis risk factors such as calcium and vitamin D intake and BMI among the study population can be determined.

\section{Methodology}

\subsection{Research design}

A cross-sectional study was carried out in Universiti Malaysia Terengganu. Samples were selected through convenience sampling between September to October 2017. Three different ethnic groups with equal proportions were selected using quota sampling. Charan and Biswas (2013) were used for sample size calculation for confidence level of $95 \%$ and precision was assumed to be 0.5 . Subject's inclusion criteria were young adults between 19 - 25 years old. A total of 198 adults with 66 Malays, 66 Chinese and 66 Indians were recruited. The present study was approved by the Research Management and Innovation Centre (RMIC) Human Ethics Committee, Universiti Malaysia Terengganu with the reference number of UMT/JKEPM/2017/6. Consent forms were signed and collected from all study participants.

\subsection{Research instrument}

A self-administered questionnaire was used as the research instrument in the present study. The two sections in the bilingual Malay and English questionnaire were used to obtain dietary intake and personal information. Part A consists of three-day food records. Amounts of focused micronutrients, namely calcium and vitamin D intake in each meal, were recorded in milligrams $(\mathrm{mg})$ and microgram $(\mu \mathrm{g})$, respectively. These values were added at the end of the three days period and compared with the RNI values. Part B was personal information including gender, race, age group, smoking status and family history of osteoporosis. Both a nominal scale and ordinal scale were used.

\subsection{Data analysis}

The data was analyzed using SPSS version 20. The Kolmogorov-Smirnov Test was used to determine the normality of the data. Descriptive tests were used to analyze the socio-demographic profiles, calcium and vitamin D intake and BMI of the respondents. MannWhitney $U$ and Kruskal-Wallis Tests were used to compare the median of the osteoporosis risk factors among adults in terms of ethnicity. In addition, the Chisquare Test was used to determine the association of ethnicity with the dietary calcium and vitamin D intake, and BMI. In all analysis, the significant value was set at 0.05 .

\section{Results}

\subsection{Socio-demographics and clinical characteristics}

A majority of respondents $(84.8 \%)$ were female. As the present study aimed to investigate the ethnic difference in osteoporosis risk, the ethnic samples were equally distributed using quota sampling. Each ethnic group contributed 66 respondents (33.3\%). All respondents were students ranging from 19 to 25 years of age. Among 198 respondents, only two respondents $(1.0 \%)$ were smokers. Both reported smoking 1-5 cigarettes per day. Lastly, it was found that a majority 
$(93.9 \%)$ of the respondents did not have a family history of osteoporosis. The data is shown in Table 1.

\subsection{Dietary intake among respondents}

The daily median energy intake of respondents was $1292 \mathrm{kcal} /$ day. The median percentage of total energy contributed by macronutrients was $48.9 \%$ for carbohydrates, $15.6 \%$ for protein, and $33.5 \%$ for fat using 3-day food record. The median calcium intake was $348.3 \mathrm{mg} /$ day, representing less than half of the RNI (34.8\%), while median vitamin D intake was only 1.37 $\mu \mathrm{g} /$ day (9.1\% of RNI). (Table 2).

\subsection{Body mass index}

The present study found that median BMI among respondents was $20.88 \mathrm{~kg} / \mathrm{m}^{2}$, considered as normal weight. Half of the respondents $(50 \%)$ had normal body weight, while almost a quarter was either underweight or overweight and obese (Table 3).

\subsection{Comparison of osteoporosis risk factors between ethnicities}

Significant differences $(p<0.05)$ in the macronutrients intakes were observed among ethnic groups. A lower intake of calories, carbohydrates, protein and fat were seen in the Indian respondents. Indian respondents also had significantly lower calcium intake than their Malay and Chinese counterparts and significantly lower vitamin D intake than Malay. It was found that there were no significant differences $(p>0.05)$ in BMI across ethnicities, as shown in Table 4.

\subsection{Associations between ethnicity and osteoporosis risk factors}

There was a significant difference $(\mathrm{p}<0.05)$ between ethnicity and calcium intake $(\mathrm{p}=0.000)$, however, no significant difference $(p>0.05)$ was found between ethnicity and dietary vitamin D intake as well as BMI of respondents, as shown in Table 5.

\section{Discussion}

In the present study, as compared to RNI, the calorie intake of respondents was low. This may because more female students $(84.8 \%)$ were involved. A previous study showed that male students had significantly higher energy intake than females (Abdull Hakim et al., 2012; Abdul Majid et al., 2016). As compared to the previous study by Zainuddin (2015), the present study shows a lower median energy and carbohydrate intake but higher fat intake among undergraduate respondents. Students may even skip meals or simply eat some biscuits. Thus, low-calorie intake may be due to students in UMT having limited food choices.
Previous studies found that the calcium intake of Malaysians averaged between $357 \mathrm{mg} /$ day to $397.2 \mathrm{mg} /$ day (Mirnalini et al., 2008; Zainuddin, 2015; Suriawati et al., 2016). Hence, $348.3 \mathrm{mg} /$ day (34.8\% RNI 2017) calcium intake by respondents in the present study was close to the average Malaysian adults' intake, which is consistently below the RNI. The findings of International Osteoporosis Foundation (IOF) research committee show that South, East, and Southeast Asia have the world's lowest average calcium intake, often less than $400 \mathrm{mg} /$ day (Balk et al., 2017). Although the calcium intake among respondents was low, it does not indicate that it will necessarily affect the serum calcium level. A previous study showed that even though the median calcium intake of respondents was only $371.9 \mathrm{mg} / \mathrm{day}$, the calcium concentration in serum still can reach $98.8 \%$ at reference level. Nevertheless, it is suggested that 400 $\mathrm{mg} /$ day of dietary calcium is actually sufficient, instead of $800 \mathrm{mg}$ /day according to RNI 2005 of calcium to maintain serum calcium concentrations at a normal level (Ang et al., 2017). For vitamin $\mathrm{D}, 1.37 \mu \mathrm{g} /$ day intake was not within the normal range for the recommended intake of Malaysian population and is far from RNI 2017. The results of the previous study among postmenopausal women, pregnant women as well as adolescent were in accordance with the present study with the majority of respondents fail to meet the RNI of Malaysia for dietary vitamin D (Rahman et al., 2004; Zaleha et al., 2015; Suriawati et al., 2016). Therefore, interventions and stricter reinforcements of existing guidelines for vitamin D supplementation are needed in Malaysia, especially for groups at risk of vitamin D insufficiency or deficiency.

The lower intake of calorie, carbohydrate, protein and fat were seen in the Indian respondents. As shown in a study by Moy et al. (2009), Indian undergraduates were more likely to skip breakfast compared to their Chinese counterparts. The same habit can actually be observed from their three-day food record in the present study. Malays had significantly higher calorie and fat intake than Chinese and Indian. Differences in food availability, cultural preferences and socioeconomic factors also contribute to differences in dietary intake between ethnic groups within and between countries (Redmond et al., 2014). From the result of three-day food record in the present study, most of the Chinese and Indian respondents cooked their own meals rather than eating out. Additionally, the frequency of fast-food consumption was also lower among Chinese and Indian respondents as compared to their Malay counterparts.

In terms of calcium and vitamin D intake, Indians had a significant lower calcium intake than Malays and Chinese, as well as significantly lower vitamin D intake 
Table 1. Demographic characteristics of the respondents

\begin{tabular}{|c|c|c|}
\hline Category & Number of respondents $(n=198)$ & Percentage $(\%)$ \\
\hline \multicolumn{3}{|l|}{ Gender } \\
\hline Male & 30 & 15.2 \\
\hline Female & 168 & 84.8 \\
\hline \multicolumn{3}{|l|}{ Race } \\
\hline Malay & 66 & 33.3 \\
\hline Chinese & 66 & 33.3 \\
\hline Indian & 66 & 33.3 \\
\hline \multicolumn{3}{|l|}{ Age (Year) } \\
\hline 19 & 9 & 4.5 \\
\hline 20 & 68 & 34.3 \\
\hline 21 & 28 & 14.1 \\
\hline 22 & 48 & 24.2 \\
\hline 23 & 38 & 19.2 \\
\hline 24 & 2 & 1 \\
\hline 25 & 5 & 2.5 \\
\hline \multicolumn{3}{|l|}{ Highest education level } \\
\hline$<\mathrm{PMR}$ & 0 & 0 \\
\hline SPM & 6 & 3 \\
\hline STPM/ Matriculation & 188 & 95 \\
\hline Diploma & 0 & 0 \\
\hline Bachelor degree & 0 & 0 \\
\hline Master or higher & 1 & 0.5 \\
\hline Others & 3 & 1.5 \\
\hline \multicolumn{3}{|l|}{ Smoking status } \\
\hline Yes & 2 & 1 \\
\hline No & 196 & 99 \\
\hline \multicolumn{3}{|c|}{ Family history of osteoporosis } \\
\hline Yes & 12 & 6.1 \\
\hline No & 186 & 93.9 \\
\hline
\end{tabular}

Table 2. Dietary intake among respondents

\begin{tabular}{lcc}
\hline \multicolumn{1}{c}{ Dietary intake } & Median (IQR) & Total energy contribution (\%) \\
\hline Calorie intake (kcal/day) & $1292(546)$ & - \\
Carbohydrate intake (g/day) & $158(64)$ & $48.9 \%$ \\
Protein intake (g/day) & $51(27)$ & $15.6 \%$ \\
Fat intake (g/day) & $48(28)$ & $33.5 \%$ \\
\hline Calcium intake & $348.3(235.1) \mathrm{mg} /$ day & RNI (Malaysia): $1000 \mathrm{mg} /$ day \\
& $\left(25^{\text {th }}-75^{\text {th }}\right.$ percentile RNI) & RDA (US): $1000 \mathrm{mg} /$ day \\
Vitamin D intake & $1.37(1.79) \mu \mathrm{g} /$ day & RNI (Malaysia): $15 \mu \mathrm{g} /$ day \\
& $\left(<25^{\text {th }}\right.$ percentile RNI) & RDA (US): $15 \mu \mathrm{g} /$ day \\
\hline
\end{tabular}

Table 3. BMI classification among respondents

\begin{tabular}{lcc}
\hline Classification & Number of respondents $(\mathrm{n}=198)$ & Percentage (\%) \\
\hline Underweight & 49 & 24.7 \\
Normal BMI & 99 & 50 \\
Overweight and obese & 50 & 25.3 \\
Total & 198 & 100 \\
\hline
\end{tabular}


Table 4. Comparison of osteoporosis risk factors between ethnicity

\begin{tabular}{|c|c|c|c|c|}
\hline \multirow{2}{*}{ Comparison } & \multicolumn{3}{|c|}{ Median (Interquartile range) } & \multirow{2}{*}{ Sig. } \\
\hline & Malay & Chinese & Indian & \\
\hline \multicolumn{5}{|l|}{ Dietary intake } \\
\hline Calorie intake & $1537.07(571.57)^{\mathrm{a}}$ & $1308.10(420.28)^{b}$ & $1009.78(332.63)^{\mathrm{c}}$ & $0.000 *$ \\
\hline Carbohydrate intake & $194.04(81.92)^{\mathrm{a}}$ & $160.55(56.18)^{\mathrm{a}}$ & $134.20(42.85)^{\mathrm{b}}$ & $0.000^{*}$ \\
\hline Protein intake & $64.31(21.80)^{\mathrm{a}}$ & $51.69(24.35)^{\mathrm{a}}$ & $38.98(14.39)^{\mathrm{b}}$ & $0.000^{*}$ \\
\hline Fat intake & $62.14(26.47)^{\mathrm{a}}$ & $48.08(25.74)^{\mathrm{b}}$ & $35.38(17.24)^{\mathrm{c}}$ & $0.000^{*}$ \\
\hline Calcium intake (mg/day) & $440.4(250.37)^{\mathrm{a}}$ & $362.3(188.09)^{\mathrm{a}}$ & $243.5(125.72)^{b}$ & $0.000^{*}$ \\
\hline Vitamin D intake ( $\mu \mathrm{g} /$ day $)$ & $2.15(2.74)^{\mathrm{a}}$ & $1.37(1.15)^{\mathrm{ab}}$ & $1.14(1.00)^{\mathrm{b}}$ & $0.004^{*}$ \\
\hline BMI & $21.64(7.37)$ & $20.70(5.20)$ & $20.95(5.46)$ & 0.551 \\
\hline
\end{tabular}

${ }^{*} \mathrm{p}<0.05$ indicates significant difference by Kruskal-Wallis Test. Letters with superscript $\mathrm{a}, \mathrm{b}$ and $\mathrm{c}$ indicate significant differences between ethnic groups by Mann-Whitney U test.

Table 5. Association between ethnicity with osteoporosis risk factors

\begin{tabular}{|c|c|c|c|c|c|c|c|c|}
\hline \multirow{3}{*}{ Characteristics } & \multicolumn{6}{|c|}{ Ethnicity } & \multicolumn{2}{|c|}{ Pearson Chi-square } \\
\hline & \multicolumn{2}{|c|}{ Malay } & \multicolumn{2}{|c|}{ Chinese } & \multicolumn{2}{|c|}{ Indian } & \multirow{2}{*}{$\chi^{2}$} & \multirow{2}{*}{$\mathrm{p}$ value } \\
\hline & $\mathrm{n}$ & $\%$ & $\mathrm{n}$ & $\%$ & $\mathrm{n}$ & $\%$ & & \\
\hline \multicolumn{9}{|l|}{ Dietary intake } \\
\hline$\%$ calcium intake with reference to RNI & & & & & & & 40.178 & $0.000^{*}$ \\
\hline$<25 \%$ & 5 & 7.6 & 12 & 18.2 & 34 & 51.5 & & \\
\hline $25-75 \%$ & 54 & 81.8 & 46 & 69.7 & 32 & 48.5 & & \\
\hline$>75 \%$ & 7 & 10.6 & 32 & 12.1 & 0 & 0 & & \\
\hline$\%$ vitamin D intake with reference to RNI & & & & & & & 5.184 & 0.075 \\
\hline$<25 \%$ & 49 & 74.2 & 57 & 86.4 & 58 & 87.9 & & \\
\hline$>25 \%$ & 17 & 25.8 & 9 & 13.6 & 8 & 12.1 & & \\
\hline BMI & & & & & & & 6.374 & 0.383 \\
\hline Underweight & 17 & 25.8 & 17 & 25.8 & 15 & 22.7 & & \\
\hline Normal & 30 & 45.5 & 34 & 51.5 & 35 & 53 & & \\
\hline Overweight & 9 & 13.6 & 11 & 16.7 & 13 & 19.7 & & \\
\hline Obese & 10 & 15.2 & 4 & 6.1 & 3 & 4.5 & & \\
\hline
\end{tabular}

${ }^{*} \mathrm{p}<0.05$ indicates significant association by Chi-Square Test. 0 cells $(0.0 \%)$ have expected count less than 5.

than Malays. The low calcium intake of Indian respondents was mainly due to less calcium-rich food consumption such as milk, dairy products and also fish, as reported in their three days food record. Moreover, the survey found that consumption of fish among Malays was significantly higher compared with the Chinese and Indian ethnic groups (Ahmad et al., 2016). Hence, based on supporting findings from the previous study, it can still be concluded that Indians might not consume an adequate amount of calcium and vitamin D compared with other major ethnicities in Malaysia. When the data of three-day food record was analyzed to determine food sources of vitamin D intake among respondents, the sources were found to be primarily sardine, bread, milk, egg, fried catfish or fried mackerel. So, the Indian respondents should increase consumption of foods high in calcium and vitamin D like sardine and milk, as well as vitamin D fortified foods such as yogurt and milk products. Nutrition information and nutrient claims should be observed before buying food products in the marketplace. They should try to choose products high in vitamin D or source of vitamin D claim.
The present study found a significant association ( $\mathrm{p}<$ 0.05 ) between ethnicity and calcium intake of respondents. These results are supported by studies by Newby et al. (2012) and Raoof (2013). A possible explanation is that dietary intake patterns depend on religion, cultural context and social milieu (Mullin et al., 2014). However, no significant association was found between ethnicity and vitamin D intake. Thus, even though Table 4 shows that significant ethnic differences in vitamin $D$ intake $(p<0.05)$, these differences actually without association with their ethnicity. A previous study found that fish consumption patterns were significantly associated with ethnicity (Ahmad et al., 2016). Therefore, the differences in vitamin D intake among respondents might be due to the difference in fish consumption pattern. There are also some other factors that will affect the vitamin D intake among the ethnic groups. For example, vitamin D intake was associated with dietary patterns. High consumption levels of milk, dairy products, whole grains, and fish are associated with higher consumption of vitamin D (Denova-Gutiérrez et al., 2016). 
The findings of the Malaysian Adult Nutrition Survey (MANS) reported that BMI among Malaysian adult was $24.37 \mathrm{~kg} / \mathrm{m}^{2}$ with $38.9 \%$ were obese or overweight (Azmi et al., 2009). Similar to the results in the present study, a majority of the respondents had normal BMI, but the percentage of overweight or obese was lower than previous studies.

Medians of BMI were not significantly different among ethnics. The similar result was obtained from a research in Singapore reported that differences in BMI among three ethnic groups were not statistically significant (Hong et al., 2004). However, a study by Seo and Torabi (2006) found a significant difference in the mean BMI of different ethnic groups. The ethnic groups involved were Hispanics, non-Hispanic whites and nonHispanic blacks. Another study also stated that significant racial or ethnic differences were found in both measured and self-reported BMIs. In the study, the ethnic group involved were White, Black, Hispanic, Asian and Native American (Richmond et al., 2015). The discrepancies found in the previous study compared with the present respondents are probably due to the characteristics of respondents. When compared with the obesity rates in the WHO report, the overall obesity rate for Malaysian adults aged 18-59 years was below those for the developed and industrialized countries, particularly the United States (Azmi et al., 2009).

Associations between ethnicity and BMI have not been as widely studied, but several studies have compared health and religiosity. Previous studies have shown that religion has been associated with health behaviors included eating habits and physical activity as well as obesity in the African American population (Dodor, 2012). From this, we can predict that there should be an association between ethnicity and BMI, suggesting the importance of studying associations between religious life and BMI.

New imaging technologies have determined ethnic differences in terms of bone geometry, volumetric density, microarchitecture, and bone strength which may contribute to a better understanding of ethnic differences in fracture risk. Factors associated with ethnicity also affect BMD and fracture risk through direct and indirect mechanisms (Leslie, 2012). Thus, dietary calcium intake associated with ethnicity and will most probably affect BMD and risk of osteoporosis or fracture among young adults.

\section{Conclusion}

This study shows that calcium and vitamin D intake of young adults was only $34.8 \%$ and $9.1 \%$ of RNI, respectively. The addition of vitamin D in the Malaysian
Food Composition Database should be emphasized to encourage more local research on dietary intake of vitamin, D due to the low intake level and low fulfillment of latest RNI among Malaysians. There were significant differences between ethnicity and dietary intake. Indians had significantly lower macronutrients and calcium intake than Malays and Chinese. Thus, Indian students have a relatively high risk of osteoporosis, as they tend to eat fewer calcium-rich foods than their Malay and Chinese counterparts. In theory, this factor should increase the risk of developing osteoporosis.

\section{Acknowledgment}

The authors would like to express their gratitude to all the young adult respondents for their participation, full cooperation, and patience with the study.

\section{References}

Abdul Majid, H., Ramli, L., Ying, S.P., Su, T.T., Jalaludin, M.Y. and Mohsein, N.A.S.A. (2016). Dietary intake among adolescents in a middleincome country: An outcome from the Malaysian health and adolescents longitudinal research team study (the MyHeARTs Study). PloS One, 11(5), e0155447. https://doi.org/10.1371/ journal.pone. 0155447

Abdull Hakim, N.H., Muniandy, N.D. and Ajau, D. (2012). Nutritional status and eating practices among university students in selected universities in Selangor, Malaysia. Asian Journal of Clinical Nutrition, 4(3), 77-87. https://doi.org/10.3923/ ajcn.2012.77.87

Ahmad, N.I., Wan Mahiyuddin, W.R., Tengku Mohamad, T.R., Ling, C.Y., Daud, S.F., Hussein, N.C., Abdullah, N.A., Shaharudin, R. and Sulaiman, L.H. (2016). Fish consumption pattern among adults of different ethnics in Peninsular Malaysia. Food and Nutrition Research, 60(1), 32697. https:// doi.org/10.3402/fnr.v60.32697

Ang, S.Y., Khairil, S.K. and Hayati, M.Y. (2017). Evaluation of dietary intake and quality of life on risk of osteoporosis among adults in Universiti Malaysia Terengganu. Malaysian Applied Biology Journal, 46(3), 123-129.

Assomaning, K., Bertone-Johnson, E.R., Nasca, P.C., Hooven, F. and Pekow, P.S. (2006). The association between body mass index and osteoporosis in patients referred for a bone mineral density examination. Journal of Women's Health, 15(9), 1028-1034. https://doi.org/10.1089/ jwh.2006.15.1028 
Azmi, M.Y., Junidah, R., Mariam, A.S., Safiah, M.Y., Fatimah, S., Norimah, A.K., Poh, B.K., Kandiah, M., Zalihah, M.S., Wan Abdul Manan, W., Tahir, A. and Haslinda, M.D. (2009). Body mass index (BMI) of adults: Findings of the Malaysian Adult Nutrition Survey (MANS). Malaysian Journal of Nutrition, 15 (2), 97-119.

Balk, E.M., Adam, G.P., Langberg, V.N., Earley, A., Clark, P., Ebeling, P.R., Mithal, A., Rizzoli, R., Zerbini, C.A.F., Pierroz, D.D. and Dawson-Hughes, B. (2017). Global dietary calcium intake among adults: a systematic review. Osteoporosis International, 28(12), 3315-3324. https:// doi.org/10.1007/s00198-017-4230-x

Charan, J. and Biswas, T. (2013). How to calculate sample size for different study designs in medical research? Indian Journal of Psychological Medicine, 35(2), 121-126. https:// doi.org/10.4103/0253-7176.116232

Chee, W.S.S., Chong, P.N., Chuah, K.A., Karupaiah, T., Mustafa, N., Suniza, S., Chinna, K., Horcajada, M.N., Ameye, L. and Offord-Cavin, E. (2010). Calcium intake, vitamin D and bone health status of post-menopausal Chinese women in Kuala Lumpur. Malaysia Journal of Nutrition 16(2): 233242.

Denova-Gutiérrez, E., Clark, P., Muñoz-Aguirre, P., Flores, M., Talavera, J.O., Chico-Barba, L.G., Riva, R., Ramirez, P. and Salmerón, J. (2016). Dietary patterns are associated with calcium and vitamin D intake in an adult Mexican population. Nutrición Hospitalaria, 33(3), 663-670.

Dodor, B. (2012). The impact of religiosity on health behaviors and obesity among African Americans. Journal of Human Behavior in the Social Environment, 22(4), 451-462. https:// doi.org/10.1080/10911359.2012.664977

Ferrari, S., Bianchi, M.L., Eisman, J.A., Foldes, A.J., Adami, S., Wahl, D.A., Stepan, J.J., de Vernejoul, M.C. and Kaufman, J.M. (2012). IOF Committee of Scientific Advisors Working Group on Osteoporosis Pathophysiology. Osteoporosis in young adults: pathophysiology, diagnosis, and management. Osteoporosis International, 23(12), 2735-2748. https://doi.org/10.1007/s00198-012-2030-x

Fong, C.Y., Kong, A.N., Poh, B.K., Mohamed, A.R., Khoo, T.B., Ng, R.L., Noordin, M., Nadarajaw, T. and Ong, L.C. (2016). Vitamin D deficiency and its risk factors in Malaysian children with epilepsy. Epilepsia, 57(8), 1271-1279. https:// doi.org/10.1111/epi.13443

Green, T.J., Skeaff, C.M., Rockell, J.E., Venn, B.J., Lambert, A., Todd, J., Khor, G.L., Loh, S.P.,
Muslimatun, S., Agustina, R. and Whiting, S.J. (2008). Vitamin D status and its association with parathyroid hormone concentrations in women of child-bearing age living in Jakarta and Kuala Lumpur. European Journal of Clinical Nutrition, 62 (3), 373-378. https://doi.org/10.1038/sj.ejcn.1602696

Hawa, M., Sakinah, H. and Hermizi, H. (2013). Calcium and Vitamin D Status of Kelantanese Malay Women from Low Income Family: A Population-Based Study. Journal of Aging Research and Clinical Practice, 2(2), 191-196.

Hong, C.Y., Chia, K.S., Hughes, K. and Ling, S.L. (2004). Ethnic differences among Chinese, Malay and Indian patients with type 2 diabetes mellitus in Singapore. Singapore Medical Journal, 45(4), 154160.

International Osteoporosis Foundation. (2013). Malaysia. Retrieved on 15 April 2017 from website: https:// www.iofbonehealth.org/sites/default/files/media/ PDFs/Regional\%20Audits/2013-Asia_Pacific_Audit -Malaysia_0_0.pdf.

International Osteoporosis Foundation. (2017). Qualeffo41 Scoring Algorithm. Retrieved on 15 December 2017 from website: https://www.iofbonehealth.org/ quality-life-questionnaires-qualeffo- 41 .

Kamau, E. (2011). Osteoporosis in the elderly, pharmacological and non-pharmacological prevention and treatment. Human Ageing and Elderly Services, Kenya: BSc. Thesis.

Khan, Y.H., Sarriff, A., Khan, A.H. and Mallhi, T.H. (2014). Knowledge, attitude and practice (KAP) survey of osteoporosis among students of a tertiary institution in Malaysia. Tropical Journal of Pharmaceutical Research, 13(1), 155-162. https:// doi.org/10.4314/tjpr.v13i1.22

Kling, J.M., Clarke, B.L. and Sandhu, N.P. (2014). Osteoporosis prevention, screening and treatment: a review. Journal of Women's Health, 23(7), 563-572. https://doi.org/10.1089/jwh.2013.4611

Lau, E. M. C., Lee, J. K., Suriwongpaisal, P., Saw, S. M., Das De, S., Khir, A. and Sambrook, P. (2001). The incidence of hip fracture in four Asian countries: the Asian Osteoporosis Study (AOS). Osteoporosis International, 12(3), 239-243. https:// doi.org/10.1007/s001980170135

Leslie, W.D. (2012). Ethnic differences in bone massclinical implications. The Journal of Clinical Endocrinology and Metabolism, 97(12), 4329-4340. https://doi.org/10.1210/jc.2012-2863

Mahdy, Z.A., Basri, H., Md Isa, Z., Ahmad, S., Shamsuddin, K. and Mohd Amin, R. (2014). Antenatal calcium intake in Malaysia. Journal of Obstetrics and Gynaecology Research, 40(4), 983- 
987. https://doi.org/10.1111/jog.12277

Mirnalini, J.K., Zalilah, M.S., Safiah, M.Y., Tahir, A., Siti, H.M., Siti, R.D., Khairul Zarina, M.Y., Mohd Hasyami, S. and Normah, H. (2008). Energy and nutrient intakes: Findings from the Malaysian Adult Nutrition Survey (MANS). Malaysian Journal of Nutrition, 14(1), 1-24.

Moy, F.M., Surin, J., Ismail, Y., Mahad, R., Tie, F.H. and Wan Ismail, W.M.A. (2009). Breakfast skipping and its associated factors among undergraduates in a public university in Kuala Lumpur. Malaysian Journal of Nutrition, 15(2), 165-174.

Mullin, G.E., Cheskin, L.J. and Matarese, L.E. (2014). Introduction to Integrative Weight Management., p. 448. USA: Springer Science and Business.

Muslim, D., Mohd, E., Sallehudin, A., Muzaffar, T. T. and Ezane, A. (2012). Performance of Osteoporosis Self-Assessment Tool for Asian (OSTA) for primary osteoporosis in post-menopausal Malay women. Malaysian Orthopaedic Journal, 6(1), 3539. https://doi.org/10.5704/MOJ.1203.011

National Coordinating Committee on Food and Nutrition Malaysia (NCCFM) (2017). A Report of the Technical Working Group on Nutritional Group on Nutritional Guidelines. Putrajaya, Malaysia: Ministry of Health Malaysia.

Newby, P.K., Noel, S.E., Grant, R., Judd, S., Shikany, J.M. and Ard, J. (2012). Race and region have independent and synergistic effects on dietary intakes in black and white women. Nutrition Journal, 11(1), 25-37. https://doi.org/10.1186/14752891-11-25

Nurbazlin, M., Chee, W.S.S., Rokiah, P., Tan, A.T.B., Chew, Y.Y., Siti Nusaibah, A.R. and Chan, S.P. (2013). Effects of sun exposure on $25(\mathrm{OH})$ vitamin $\mathrm{D}$ concentration in urban and rural women in Malaysia. Asia Pacific Journal of Clinical Nutrition, 22(3), 391-399.

Rahman, S.A., Chee, W.S.S., Yassin, Z. and Chan, S.P. (2004). Vitamin D status among postmenopausal Malaysian women. Asia Pacific Journal of Clinical Nutrition, 13(3), 255-260.

Raoof, F. (2013). Calcium intake patterns in association with demographic and socioeconomic factors in US population 2-69 years of age: A Cross-Sectional Study. Atlanta, Georgia: Georgia State University, MSc. Thesis

Redmond, J., Jarjou, L.M.A., Zhou, B., Prentice, A. and Schoenmakers, I. (2014). Ethnic differences in calcium, phosphate and bone metabolism. Proceedings of the Nutrition Society, 73(2), 340-351. https://doi.org/10.1017/S0029665114000068

Richmond, T.K., Thurston, I., Sonneville, K., Milliren,
C.E., Walls, C.E. and Austin, S.B. (2015). Racial/ ethnic differences in accuracy of body mass index reporting in a diverse cohort of young adults. International Journal of Obesity, 39(3), 546-548. https://doi.org/10.1038/ijo.2014.147

Seo, D.C. and Torabi, M.R. (2006). Racial/ethnic differences in body mass index, morbidity and attitudes toward obesity among US adults. Journal of the National Medical Association, 98(8), 1300-1308.

Shafinaz, I.S. and Moy, F.M. (2016). Vitamin D level and its association with adiposity among multiethnic adults in Kuala Lumpur, Malaysia: a cross sectional study. BMC Public Health, 16(1), 232. https://doi.org/10.1186/s12889-016-2924-1

Sozen T., Ozıs1k, L. and Basaran, N.C. (2017). An overview and management of osteoporosis. European Journal of Rheumatology, 4(1), 46-52. https://doi.org/10.5152/eurjrheum.2016.048

Suriawati, A.A., Abdul Majid, H., Al-Sadat, N., Mohamed, M.N.A. and Jalaludin, M.Y. (2016). Vitamin D and calcium intakes, physical activity, and calcaneus BMC among school-going 13-year old Malaysian adolescents. Nutrients, 8(10), 666-679. https://doi.org/10.3390/nu8100666

Zainuddin, A.A. (2015). Current nutrient intake among Malaysia adult: Finding from MANS 20. Medical Journal of Malaysia, 70(1). 1-2.

Zaleha, M.I., Khadijah, S., Bukhary, I.N., Khor, G.L., Zaleha, A.M., Haslinda, H., Hana, N.S. and Faisal, G.H. (2015). Development and validation of a food frequency questionnaire for vitamin $\mathrm{D}$ intake among urban pregnant women in Malaysia. Malaysian Journal of Nutrition, 21(2), 179-190. 